Pendas : Jurnal IImiah Pendidikan Dasar,

ISSN Cetak : 2477-2143 ISSN Online : 2548-6950

Volume III Nomor 2, Desember 2018

\title{
PENGARUH KECERDASAN EMOSIONAL TERHADAP MOTIVASI BELAJAR \\ MATEMATIKA SISWA KELAS IV SEKOLAH DASAR ISLAM BABUSSALAM \\ KECAMATAN DURENAN KABUPATEN TRENGGALEK \\ TAHUN AJARAN 2017/2018
}

\author{
Muhammad Farhan Faizi \\ PGSD STKIP PGRI Tulungagung \\ mfarhanfaiz17@gmail.com
}

\begin{abstract}
Mathematics is one of compulsory science for all human beings. However, this science is often a scourge for students so that the motivation of students to this science is low. Emotional intelligence is one of the factors that influence the high intrinsic motivation that the learners have. From the exposure, the researchers took the formulation of the problem "Is there any influence of emotional intelligence on the motivation (intrinsic) learning mathematics fourth grade students Islamic Elementary School Babussalam Durenan?". This research uses quantitative research with survey method on fourth grade students of SDI Babussalam. In collecting data using questionnaire in the form of questionnaire. Result of $t$ analysis (t $\left.t_{\text {count }}\right) 6,999>t_{\text {table }} 2.032$ at 5\% significant level with $d f=N-k=36-2=34$ then alternative hypothesis accepted which mean existence of influence of signivikan given by emotional intelligence to motivation learn student of fourth grade Islamic Elementary School Babussalam Pandean Durenan Sub-district of Tenggalek Regency. In the activity of teaching and learning, there should be special attention to the development of intellectual intelligence and social intelligence of children.
\end{abstract}

Keywords: Emotional Intelligence, Motivational Learning Mathematics.

\begin{abstract}
ABSTRAK
Matematika merupakan salah satu ilmu pengetahuan wajib bagi seluruh manusia.Akan tetapi mata pelajaran ini malah sering menjadi momok bagi peserta didik sehingga motivasi peserta didik terhadap ilmu ini rendah.Kecerdasan emosional adalah salah satu factor yang mempengaruhi tinggi rendahnya motivasi intrinsic yang dimiliki peserta didik. Dari paparan tersebut peneliti mengambil rumusan masalah "Adakah pengaruh kecerdasan emosional terhadap motivasi (intrinsic) belajar matematika siswa kelas IV SDI Babussalam Durenan?".Penelitian ini menggunkan penelitian kuantitatif dengan metode survey pada siswa kelas IV SDI Babussalam.Dalam pengumpulan data menggunakan kuisioner dalam bentuk angket.Hasil analisis $t$ (thitung) $6.999>$ ttabel 2,032 pada taraf signifikan $5 \%$ dengan df $=\mathrm{N}-\mathrm{k}=36-2=34$ maka hipostesis alternatif diterima yang berarti adanya pengaruh signivikan yang diberikan kecerdasan emosional terhadap motivasi belajar matematika siswa kelas IV SDI Babussalam Pandean Kecamatan Durenan Kabupaten Tenggalek. Dalam kegitan belajar mengajar perlu ada perhatian kusus terhadap perkembangan kecerdasan intelektual dan kecerdasan social anak.
\end{abstract}


Pendas : Jurnal IImiah Pendidikan Dasar,

Kata kunci :Kecerdasan Emosional, Motivasi Belajar Matematika.

\section{A. Pendahuluan}

Matematika merupakan salah satu mata pelajaran yang ada hampir diseluruh Negara didunia, tidak terkecuali di Indonesia.Namun rasa bosan dan takut sering dirasakan sebagian besar siswa ketika belajar matematika karena anggapan bahwa matematika merupakan pelajaran yang sulit dan hafalan banyak rumus.Untuk memahaminyapun membuwat siswa kuwalahan dan menurunkan minat siswa sehingga hasil belajar siswa kurang maksimal.

Banyak anggapan bahwa untuk menjadi ahli matematika harus memiliki kecerdasan intelektual yang tinggi, padahal ada peran kecerdasan emosional yang melengkapi. Mashar (2011) mengemukakan bahwa "kecerdasan emosional adalah kemampuan untuk mengenali, mengolah, dan mengontrol emosi agar mampu merespons secara positif setiap kondisi yang merangsang munculnya emosiemosi". Kecerdasan emosional ini dapat diartikan sebagai kecerdasan hati, hati yang tetap tenang dikala masalah bergejolak sehingga orang tersebut mampu tetap berpikir jernih dengan kepala yang tetap dingin. Seseorang yang memiliki kecerdasan emosional yang baik tentunya dia mengenali dirinya dan mampu mengontrol emosinya agar tetap dalam kondisi yang positif.

Berdasarkan observasi awal, hasil dari wawancara terhadap guru kelas IV mengungkapkan bahwa hanya beberapa siswa yang aktif dan antusias ketika pembelajaran berlangsung, beberapa siswa lebih sering izin keluar kelas, dan sebagian besar siswa adalah pasif.Hal tersebut memberikat arti secara tersairat bahwa hanya beberapa anak yang memiliki kesadaran diri untuk memotivasi diri dalam belajar matematika. Setelah beberapa siswa ditanya mengapa mereka tidak fokus pada pelajaran, mereka beralasan mata pelajaran matematika itu sulit dan membosankan.

Kecerdasan emosional pada dasarnya adalah yang bertugas mengatur motivasi dalam diri seseorang.Berdasarkan pemaparan tersebut peneliti mendapatkan rumusan masalah berikut "Adakah pengaruh kecerdasan emosional (EI) terhadap motivasi (intrinsic) belajar 
Pendas : Jurnal Ilmiah Pendidikan Dasar, ISSN Cetak : 2477-2143 ISSN Online : 2548-6950 Volume III Nomor 2, Desember 2018

matematika siswa kelas IV SDI Babussalam Durenan?"dengan tujuan untuk mengetahui adanya pengaruh kecerdasan emosional (EI) terhadap motivasi (intrinsic) belajar matematika siswa kelas IV SDI Babussalam Durenan.

Hasil penelitian diharapakan dapat memberikan manfaat kepada semua pihak yang terkait langsung dalam dunia pendidikan terkhusus untuk siswa SDI Babussalam Durenan diharapkan dapat mengembangkan ilmu pengetahuan dan memperkaya hasanah ilmiah tentang pengaruh kecerdasan emosional terhadap prestasi belajar matematika, sehingga KBM berjalan lebih efektif dan menyenangkan serta memunculkan motivasi belajar siswa.

\section{B. Landasan Teori}

\section{Matematika}

Pegertian matematika menurut para ahli yaitu :Russefendi (2003) menyatakan bahwa matematika itu terorganisasikan dari unsur-unsur yang tidak didefinisikan, defenisidefenisi, aksioma-aksioma, dan dalildalil, di mana dalil-dalil setelah dibuktikan kebenarannya berlaku secara umum. Ahli lainnya Reys (Murniati, 2007) dalam bukunya mengatakan bahwa matematika adalah telaah tentang pola dan hubungan, suatu jalan atau pola berfikir, suatu seni, suatu bahasa, dan suatu alat.

Pendapat yang ada diatas memberikan simpulan bahwa matematika adalah suatu disiplin ilmu untuk memperoleh pengetahuan dalam memahami arti dari strukturstruktur, hubungan-hubungan, simbol-simbol yang ada sehingga menyebabkan perubahan tingkah laku.

\section{Kecerdasan Emosional}

Secara etimologi kecerdasan atau intellegensi berasal dari bahasa inggris "intellegens", bahasa latin "intellectus dan intelligentia" yang memiliki arti kecerdasan.Terman berpendapat kecerdasan merupakan kemampuan seseorang untuk berfikir secara abstrak. John W Sancohk juga mengungkapkan kecerdasan adalah keahlian menyelesaikan masalah dan kemampuan untuk beradaptasi pada dan belajar dari, pengalaman hidup sehari-hari. Sedangkan menurut William Stern kecerdasan merupakan kesanggupan untuk menyesuaikan diri dengan menggunakan alat-alat berpikir yang sesuai dengan tujuannya. 
Pendas : Jurnal Ilmiah Pendidikan Dasar, ISSN Cetak : 2477-2143 ISSN Online : 2548-6950 Volume III Nomor 2, Desember 2018

Simpulan kecerdasan adalah kemampuan menerima, beradaptasi dan meresponnya dengan efektif. Ciri-ciri perilaku sebagai tanda telah dimilikinya inteligensi yang tinggi, antara lain adalah (1) adanya kemampuan untuk memahami dan menyelesaikan problem mental dengan cepat, (2) kemampuan mengingat, (3) kreatifitas yang tinggi, dan (4) imajinasi yang berkembang.

Daniel Goleman (1995. Hal.411) menganggap "emosi merujuk pada suatu perasaan dan pikiran-pikiran yang khas, suatu keadaan biologis dan psikologis dan serangkaian kecenderungan untuk bertindak". Makna paling harfiah dari emosi (Ibid. Hal. 411) didefinisikan sebagai setiap kegiatan atau pergolakan pikiran, perasaan, dan nafsu: setiap keadaan mental yang hebat atau meluap-luap.

Menurut Goleman ada ratusan emosi, namun sejumlah teoretikus mengelompokkan emosi dalam golongan-golongan besar. Golongan utama emosi dan beberapa anggota kelompoknya (Ibid. Hal. 411-412) yaitu :Amarah, Kesedihan, Rasa takut, Kenikmatan, Cinta, Terkejut, Jengkel, Malu.

Mashar (2011) mengemukakan kecerdasan emosional adalah kemampuan untuk mengenali, mengolah, dan mengontrol emosi agar mampu merespons secara positif setiap kondisi yang merangsang munculnya emosiemosi.Goleman (1995.Hal. 69) menyatakan bahwa "Keterampilan kecerdasan emosi bekerja secara sinergi dengan keterampilan kognifif, orang-orang yang berprestasi tinggi memiliki keduanya. Makin kompleks pekerjaan, makin penting kecerdasan emosi.Emosi yang lepas kendali dapat membuat orang pandai menjadi bodoh. Tanpa kecerdasan emosi, orang tidak akan mampu menggunakan kemampuan kognitif mereka sesuai dengan potensi yang maksimum.

Merujuk dari beberapa teori tentang kecerdasan emosi di atas, maka penulis menyimpulkan pengertian kecerdasan emosional sebagai kemampuan untuk memotivasi diri sendiri, dan kemampuan mengelola emosi dengan baik pada diri sendiri dan dalam hubungannya dengan orang lain.

$\begin{array}{lrr}\text { Salovey } & \text { dalam } & \text { buku Daniel } \\ \text { Goleman } & \text { (1995) } & \text { membagi }\end{array}$ kecerdasan emosional menjadi lima wilayah utama yaitu sebagai berikut: 
Pendas : Jurnal Ilmiah Pendidikan Dasar, ISSN Cetak : 2477-2143 ISSN Online : 2548-6950 Volume III Nomor 2, Desember 2018

a) Mengenali emosi diri, b) Mengelola emosi, c) Memotivasi diri sendiri, d) Membina hubungan,e) Keterampilan social.

Disamping itu, menurut Goleman (1995.Hal. 34-35) sebagai berikut: a) Kecakapan pribadi, b) Kesadaran diri, c) Pengaturan diri, d) Motivasi, e) Empati, f) Keterampilan social.

Crooks \& Stein menyatakan (Uno. 2006) bahwa hubungan motivasi dan emosi (perasaanperasaan dan gejolak yang subyektif) sangat erat sekali.Menurutnya, emosi sering kali memotivasi tindakan.Semua emosi pada dasarnya adalah dorongan untuk bertindak, rencana seketika untuk mengatasi masalah yang telah ditanamkan secara berangsur-angsur oleh evolusi. Sedangkan Gardner mencatat (Goleman.1995) bahwa inti kecerdasan antarpribadi itu mencakup "kemampuan untuk membedakan dan menanggapi dengan tepat suasana hati, temperamen, motivasi, dan hasrat orang lain".

Dari uraian di atas dapat dirumuskan bahwa seseorang yang memiliki kecerdasan emosi yang cukup berarti ia mampu memotivasi dirinya sendiri agar bertindak tepat dengan suasana hati serta mampu memanfaatkan perasaan-perasaanya untuk menuntun tingkah laku.

\section{Motivasi Belajar Matematika}

Subroto (2002) menyebutkan "Motivasi adalah suatu keadaan dalam diri pribadi seseorang atau individu yang mendorong individu tersebut melakukan aktivitas tertentu guna mencapai suatu tujuan".Motivasi dibedakan menajdi dua macam, yaitu motivasi intrinsik dan motivasi ekstrinsik.Dimyati dan Mudjiono (2002.Hal.90) "Motivasi dapat berupa dorongan-dorongan dasar atau internal dan insentif di luar diri individu atau hadiah. Sebagai suatu masalah di dalam kelas, motivasi adalah proses membangkitkan, mempertahankan, dan mengontrol minat-minat". Hamalik (1992.Hal.173) "Ada tiga komponen utama dalam motivasi yaitu kebutuhan, dorongan, dan tujuan. Kebutuhan terjadi bila individu merasa ada ketidakseimbangan antara apa yang ia miliki dan yang ia harapkan. Dorongan merupakan kekuatan mental untuk melakukan kegiatan dalam rangka mencapai tujuan.Dorongan yang berorientasi pada tujuan tersebut merupakan inti 
Pendas : Jurnal IImiah Pendidikan Dasar, ISSN Cetak : 2477-2143 ISSN Online : 2548-6950 Volume III Nomor 2, Desember 2018

motivasi". Motivasi intrinsic dan ekstrinsik berisi tentang berikut ini : Motivasi intrinsik berisi: (a) penyesuaian tugas dengan minat, (b) perencanaan yang penuh variasi, (c) umpan balik atas respon siswa, (d) kesempatan respon peserta didik yang aktif, dan (e) kesempatan peserta didik untuk menyesuaikan tugas pekerjaannya. Sedangkan motivasi ekstrinsik berisi: (a) penyesuaian tugas dengan minat, (b) perencanaan yang penuh variasi, (c) respon siswa, (d) kesempatan peserta didik yang aktif, (e) kesempatan peserta didik untuk menyesuaikan tugas pekerjaannya, dan (f) adanya kegiatan yang menarik dalam belajar. Uno (2006 Hal.9).

Berdasarkan teori-teori motivasi yang telah dikemukakan di atas dapat disimpulkan, motivasi merupakan suatu dorongan yang timbul oleh adanya rangsangan dari dalam maupun dari luar sehingga seseorang berkeinginan untuk merespon agar mencapai tujuan.

Hakikat motivasi belajar adalah dorongan internal dan eksternal pada peserta didik yang sedang belajar untuk mengadakan perubahan tingkah laku. Indikator motivasi belajar dapat diklasifikasikan sebagai berikut: (a) adanya hasrat dan keinginan berhasil, (b) adanya dorongan dan kebutuhan dalam belajar, (c) adanya harapan dan citacita masa depan, (d) adanya penghargaan dalam belajar, (e) adanya kegiatan yang menarik dalam belajar, (f) adanya lingkungan belajar yang kondusif, sehingga memungkinkan seseorang siswa dapat belajar dengan baik. (Uno, 2006 Hal.9).

Motivasi belajar merupakan segi kejiwaan yang mengalami perkembangan, artinya terpengaruh oleh kondisi fisiologis dan kematangan psikologis siswa. Unsurunsur yang mempengaruhi motivasi belajar Dimyati dan Mudjiono (2008.Hal. 97-100) diantaranya adalah: a). Cita-cita, b). Kemampuan Siswa, c). Kondisi Siswa, d). Kondisi Lingkungan Siswa, e). Unsur-unsur Dinamis dalam Belajar dan Pembelajaran, f). Upaya Guru dalam Membelajarkan Siswa.

\section{Metode Penelitian}

Penelitian ini dilaksanakan di kelas IV SDI Babussalam Pandean, Kecamatan Durenan, Kabupaten Trenggalek. 
Pendas : Jurnal Ilmiah Pendidikan Dasar, ISSN Cetak : 2477-2143 ISSN Online : 2548-6950 Volume III Nomor 2, Desember 2018

Penelitian ini dilaksanakan pada bulan April 2018 sampai Juni 2018.Upaya menjelaskan pola hubungan fungsional antarvariabel dalam penelitian ini menggunakan metode survei parametric nonexperimen dengan pendekatan kuantitatif.Populasi penelitian ini adalah siswa kelas IV dengan jumlah 36 siswa yang terbagi menjadi dua kelas dan keseluran populasi menjadi sampel karena sampling yang digunakan adalah sampling jenuh.Penelitian ini menggunakan dua variabel, yaitu kecerdasan emosional $(\mathrm{X})$ dan motivasi belajar Matematika (Y).teknik yang digunakan untuk mengumpulkan data menggunakan teknik angket. Sebelum angket dibagikan ke responden penelitian angket perlu diuji prasyarat berupa uji validitas dan reliabilitas ke 10 responden dengan tujuan untuk mengetahui valid dan reliablenya angket yang akan digunakan untuk penelitian. Penelitian ini menggunakan SPSS for Windows 20.0 karena data yang diambil merupakan data kuantitatif, sedangkan analisis yang digunakan adalah korelasi product moment. Sebelum melakukan analisis data maka terlebih dahulu dilakukan uji prasyarat analisis yang meliputi uji normalitas, uji linieritas dan uji homogenitas.

\section{Hasil dan Pembahasan}

1. Hasil Penelitian

Uji validitas dan reliabilitas menggunakan SPSS for Windows 20.0 diperoleh bahwa 26 item angket kecerdasan emosional dan 15 item angket motivasi belajar memiliki nilai rhitung lebih besar dari rtabel (rhitung $>$ 0,632). Maka dapat disimpulkan bahwa dari hasil uji validitas untuk angket yang dibagikan ke 10 responden dan terdiri dari 41 item pertanyaan adalah valid.

Uji reliabilitas ini dinyatakan reliabel apabila nilai Cronbach's Alpha (a) yang diperoleh $\geq 0,632$. Berikut disajikan data hasil uji reliabilitas angket sebagaimana pada tabel $\mathrm{d} .1$ berikut:

Tabel d.1 Hasil Uji Reliabilitas Kecerdasan Emosional (X) dan Motivasi Belajar (Y)

\begin{tabular}{|c|c|c|}
\hline variabel & $\begin{array}{c}\text { Cronbach's } \\
\text { Alpha (a) }\end{array}$ & $\begin{array}{l}\text { jumlah } \\
\text { item }\end{array}$ \\
\hline$X$ & 0,965 & 26 \\
\hline$Y$ & 0,958 & 15 \\
\hline
\end{tabular}


Pendas : Jurnal IImiah Pendidikan Dasar, ISSN Cetak : 2477-2143 ISSN Online : 2548-6950 Volume III Nomor 2, Desember 2018

Berdasarkan table 4.3 nilai Realiability Statistic menunjukkan nilai Cronbach's Alpha sebesar 0,965 dan 0,958 lebih besar dari nilai signifikasi 0,632 dengan keterangan amat tinggi. Maka dapat disimpulkan bahwa item pada instrumen sudah reliabel (layak) sehingga angket dapat digunakan untuk mengumpulkan data.

Uji normalitas merupakan uji kenormalan distribusinya.Uji normalitas dilakukan dengan program SPSS for Windows 20.0 dengan teknik analisis Kolmogorov-Sminov. Berikut ini hasil uji normalitas:

Tabel d.2 Rangkuman Hasil Uji

Normalitas Variabel $\mathbf{X}$ dan

\begin{tabular}{rcc}
\multicolumn{3}{c}{ Variabel $\mathbf{Y}$} \\
\hline & $\begin{array}{c}\text { Kecerdasan } \\
\text { emosional } \\
(\mathrm{X})\end{array}$ & $\begin{array}{c}\text { Motivasi } \\
(\mathrm{Y})\end{array}$ \\
\hline $\mathrm{N}$ & 36 & 36 \\
\hline $\begin{array}{c}\text { Asymp. } \\
\text { Sig. (2- } \\
\text { tailed) }\end{array}$ & 0.696 & 0.520 \\
\hline
\end{tabular}

Berdasarkan tabel d.2 diketahui nilai signifikasi variabel $>0,05$ yang berarti data berdistribusi normal.

Uji linieritas menggunakan SPSS for Windows 20.0. Hasil uji linieritas sebagaimana tabel d.3 berikut:
Tabel d.3 Rangkuman Hasil Uji

Linieritas Variabel $X$ terhadap

Variabel $Y$

\begin{tabular}{lcc}
\hline & Df & Sig. \\
\hline $\begin{array}{l}\text { Deviation } \\
\text { from }\end{array}$ & 35 & 0.637 \\
Linearity & & \\
\hline
\end{tabular}

Berdasarkan pada tabel d.3 diperoleh nilai signifikasi 0,637> 0,05, maka terdapat hubungan linier secara signifikan antara variabel $(\mathrm{X})$ terhadap variabel $(\mathrm{Y})$.

Tabel d.4 Rangkuman Hasil

Test of Homogeneity of

\begin{tabular}{|c|c|c|c|c|}
\hline Variabel & $\begin{array}{l}\text { Lev- } \\
\text { ene } \\
\text { Stati- } \\
\text { stic }\end{array}$ & df1 & df2 & Sig. \\
\hline$x$ & 0.981 & 1 & 34 & 0.329 \\
\hline$Y$ & 0.064 & 1 & 34 & 0.801 \\
\hline
\end{tabular}

Suatu data dikatakan homogeny apabila nilainya $>0,05$. Dari table d.4 hasil uji homogenitas kecerdasan emosional menunjukkan nilai sig. > 0.05 yang berarti kedua variansnya adalah homogeny.

Korelasi product moment adalah hubungan secara linier antara variabel $X$ dan variabel $Y$. Analisis ini menggunakan SPSS for Windows 20.0. Hasil uji analisis korelasi linier 
Pendas : Jurnal Ilmiah Pendidikan Dasar, ISSN Cetak : 2477-2143 ISSN Online : 2548-6950 Volume III Nomor 2, Desember 2018

sederhana sebagaimana tabel berikut:

\section{Tabel d.5 Rangkuman Hasil}

Korelasi $\mathbf{X}$ terhadap $\mathbf{Y}$

\begin{tabular}{ccc} 
& \multicolumn{2}{c}{ Correlations } \\
\hline Variabel & & $\begin{array}{c}\text { Pearson } \\
\text { Correlation }\end{array}$ \\
\hline$X$ & 6 & $.768^{* *}$ \\
\hline$Y$ & 6 & $.768^{* *}$ \\
\hline
\end{tabular}

Analisa tabel d.5 di atas dapat diketahui bahwa responden sebanyak 36 menghasilkan korelasi sebesar 0,768.Untuk melakukan intepretasi hubungan antara kedua variabel tersebut dilakukan dengan melihat angka koefisien korelasi.Korelasi 0,768 masuk dalam intepretasi nilai $r$ kategori kuat. Dapat diambil kesimpulan bahwa antara pendidikan karakter $(X)$ dengan motivasi belajar (Y) mempunyai hubungan yang kuat karena mempunyai nilai korelasi sebesar 0,768, maka $\mathrm{H}_{1}$ diterima karena Ada pengaruh yang signifikan kecerdasan emosional (EI) terhadap motivasi (intrinsic) belajar matematika siswa kelas IV SDI Babussalam DurenanKabupaten Trenggalek Tahun Pelajaran 2017/2018.

\section{Pembahasan}

Berdasarkan hasil analisis yang menunjukkan hasil korelasi 0,768 dan termasuk kategori kuat diperoleh hasil bahwa, kecerdasan emosional (X) berpengaruh signifikan terhadap motivasi belajar matematika (Y) siswa kelas IV SDI Babussalam Pandean Kecamatan Durenan Kabupaten Trenggalek Tahun Pelajaran $2017 / 2018$.

Goleman (1995.Hal. menyatakan bahwa Keterampilan kecerdasan emosi bekerja secara sinergi dengan keterampilan kognifif, orang-orang yang berprestasi tinggi memiliki keduanya. Makin kompleks pekerjaan, makin penting kecerdasan emosi.Emosi yang lepas kendali dapat membuat orang pandai menjadi bodoh. Tanpa kecerdasan emosi, orang tidak akan mampu menggunakan kemampuan kognitif mereka sesuai dengan potensi yang maksimum.

Patton (1995) menyatakan Kecerdasan emosional adalah kemampuan seseorang untuk mengenali emosi diri, mengelola emosi, memotivasi diri sendiri, mengenali emosi orang lain (empati), dan kemampuan untuk membina hubungan (kerja sama) dengan orang lain. Goleman menambahkan bahwa para ahli psikologi sepakat kalau IQ hanya mendukung sekitar $20 \%$ faktor 
Pendas : Jurnal Ilmiah Pendidikan Dasar, ISSN Cetak : 2477-2143 ISSN Online : 2548-6950 Volume III Nomor 2, Desember 2018

yang menentukan keberhasilan, sedangkan $80 \%$ sisanya berasal dari faktor lain, termasuk kecerdasan emosional.

Dengan demikian dapat disimpulkan bahwa ada pengaruh kecerdasan emosional (EI) terhadap motivasi (intrinsic) belajar matematika siswa kelas IV SDI Babussalam Pandean Kecamatan

DurenanKabupaten Trenggalek Tahun Pelajaran 2017/2018.

\section{E. Kesimpulan}

Berdasarkan analisis data beserta interpretasinya, maka dari penelitian ini dapat ditarik kesimpulan bahwa ada pengaruh kecerdasan emosional terhadap motivasi belajar siswa matematika SDI Babussalam Pandean Kecamatan Durenan Kabupaten Trenggalek tahun ajaran 2017/2018. Hal tersebut ditunjukkan dari hasil korelasi Product Moment sebesar 0,768 yang mana apabila dipadukan dengan table 3.1 Interpretasi Koefisien Korelasi hasil analisis korelasi menunjukkan adanya pengaruh variable $X$ terhadap variable $\mathrm{Y}$ dalam kategori kuat maka dapat ditarik kesimpulan hipotesis alternatif $\left(\mathrm{H}_{1}\right)$ diterima.

\section{DAFTAR PUSTAKA}

DEPDIKNAS. (2006). Peratura nmenteri Pendidikan Nasional Standar Kopetensi Lulusan Untuk Satuan Pendidikan Dasar Dan Menengah. Jakarta.

Dimyati. (2006). Belajar dan Pembelajaran. Jakarta: Rineka Cipta. Jakarta.

Erman suherman dkk. (2003).

Strategi Matematik

Kontemporer. Bandung :

Universitas Pendidikan Indonesia.

Goleman, Daniel. (2017). Emotional Intelegence Cetakan 23.Jakarta : gramedia pustaka utama.

Sugiyono. (2011) .Metode Penelitian

Kuantitatif, Kualitatif Cetakan ke-13, dan R\&D. Bandung : Alfabeta.

Suryana, Irfan. (2017) .Smart=Happy. Yogyakarta : Psikologi Corner.

Uno, Hamzah. (2007). Teori Motivasi dan Pengukurannya. Bumi Aksara. Jakarta

Wahyudin, Sudrajat. (2003).

Ensiklopedi Matematika dan Peradaban Manusia.Jakarta :CV Taritu Samudera Berlian. Altundo .(2013). Pengertian Motivasi dan Macam Macam Motivasi Belajar. Diperoleh dari 
Pendas : Jurnal Ilmiah Pendidikan Dasar, ISSN Cetak : 2477-2143 ISSN Online : 2548-6950

https://www.altundo.com/pengertian-

motivasi-dan-macam-macam-

motivasi-belajar.

Kamus Q (2013). Matematika adalah

| Pengertian dan Definisi

Mathematic. Diperoleh dari

http://www.kamusq.com/2013/0

6/matematika-adalah-pengertian

-dan.html

KKBI During (2016). Diperoleh dari https://kbbi.kemdikbud.go.id/entr i/belajar

Lentera Kecil (2018). Pengertian

matematika. Diperoleh dari

https://lenterakecil.com/pengerti

an matematika/ 